\title{
Designing walkable cities and neighborhoods in the era of urban big data
}

\section{Citation}

Guan, ChengHe, Michael Keith, and Andy Hong. 2019. Designing walkable cities and neighborhoods in the era of urban big data. Urban Planning International.

\section{Permanent link}

http://nrs.harvard.edu/urn-3:HUL.InstRepos:41254716

\section{Terms of Use}

This article was downloaded from Harvard University's DASH repository, and is made available under the terms and conditions applicable to Open Access Policy Articles, as set forth at http:// nrs.harvard.edu/urn-3:HUL.InstRepos:dash.current.terms-of-use\#OAP

\section{Share Your Story}

The Harvard community has made this article openly available.

Please share how this access benefits you. Submit a story.

\section{Accessibility}




\title{
Designing walkable cities and neighborhoods in the era of urban big data
}

\author{
A special issue on Walkable Cities by Urban Planning International \\ ChengHe Guan ${ }^{12 *}$, Michael Keith ${ }^{3}$, and Andy Hong ${ }^{4}$ \\ ${ }^{1}$ NYU Shanghai \\ ${ }^{2}$ Harvard-China Project on Energy, Economy and Environment, Harvard University \\ ${ }^{3}$ PEAK, Centre on Migration, Policy and Society, University of Oxford \\ ${ }^{4}$ George Institute for Global Health, University of Oxford \\ * Corresponding author email: chenghe.guan@nyu.edu
}

\section{Keywords}

Walkable cities; walkable neighborhoods; spatial temporal scale and indicators; urban big data

\begin{abstract}
In this paper, we discuss walkable cities from the perspective of urban planning and design in the era of digitalization and urban big data. We start with a brief review on historical walkable cities schemes; followed by a deliberation on what a walkable city is and what the spatial elements of a walkable city are; and a discussion on the emerging themes and empirical methods to measure the spatial and urban design features of a walkable city. The first part of this paper looks at key urban design propositions and how they were proposed to promote walkability. The second part of this paper discusses the concept of walkability, which is fundamental to designing a walkable city. We emphasize both the physical (walkways, adjacent uses, space) and the perceived aspects (safety, comfort, enjoyment), and then we look at the variety of spatial elements constituting a walkable city. The third part of this paper looks at the emerging themes for designing walkable cities and neighborhoods. We discuss the application of urban big data enabled by growing computational powers and related empirical methods and interdisciplinary approaches including spatial planning, urban design, urban ecology, and public health. This paper aims to provide a holistic approach toward understanding of urban design and walkability, re-evaluate the spatial elements to build walkable cities, and discuss future policy interventions.
\end{abstract}

\section{Acknowledgement and Funding}

We appreciate the support from the PEAK Urban Programme, funded by UK Research and Innovation as part of the UK government's Global Challenges Research Fund. Generous funding was provided by the Harvard-China Project on Energy, Economy and Environment from the Harvard Global Institute, under an award on the theme of "China 2030/2050: Energy and Environmental Challenges for the Future". 


\section{Urban design propositions promoting walkable city form}

In the field of urban planning and design, academics and practitioners alike, the concept of walkable city has been widely recognized and applied to achieve the goal of sustainable urbanization. From the garden cities of Welwyn and Letchworth in the UK, envisaged by the social reformer Ebenezer Howard, to Le Corbusier and his Contemporary City promoted efficient urban design that favors economy of scale that warmly embraced by Fordism and Taylorism, and then to a sustainable urban design movement emerged during the post-modern era, supported by environmental reformers. All has one commonality - cities should be walkable.

\subsection{Garden city}

In the movement of garden cities, Ebenezer Howard pictured places where access to open spaces and nature prevail. One of the predominant features of the Garden City is the provision of open space. These open spaces are integral components of the city form, providing convenient pedestrian access alongside community facilities and public amenities (Bresnehan, 1995). Welwyn Garden City in the UK was founded on the promises to combine the benefits of the city and the countryside to celebrate the advantages of both urban and rural (easy access to urban amenities and to nature), see Figure 1. As Soissons (1988) more explicate stated "a town designed for healthy living and industry of a size that makes possible a full measure of social life but not larger, surrounded by a rural belt; the whole of the land being held in trust for the community". Although far from perfect, as commented by the Times in 1948, Welwyn made new (walkable) towns possible. Struggled with respect to a suitable financial model to support viable housing option, Garden cities model distinct from conventional development by allowing town government to control a number of buildings and land where new development might occurs to comprise/promote walkability of the residents.

$<$ Figure 1. Welwyn Garden City: the self-sufficient and walkable city.> Source: https://newtownherts.weebly.com/blog/the-other-golden-mile-the-factories-of-welwyngarden-city

\subsection{Neighborhood Units}

Learning from its British counterparts, American intellectuals were considering new approaches to establish communities in the United States using the concept of garden cities. In addition, they sought to apply the concept of neighborhood unit developed by Clarence Perry (Bresnehan, 1995). Perry envisaged an ideal neighborhood unit to include 4,000 to 7,000 people (a scale to support an elementary school), while multiple neighborhoods converges to form a larger community or town. Even though Radburn, New Jersey was inevitably affected by the motor age, hence departing from some of the original garden city concept, it emphasized the spatial design that fosters social interactions, see Figure 2. One concerted effort was the complete 
separation of pedestrian from vehicular traffic. This is realized through the application of super block and vertical intersection. The layout of superblock is essentially irregular shaped blocks connected by curvilinear network of streets. The vertical intersections are composed of an overpass and an underpass. Lewis Mumford described Radburn as "the first major departure in city planning since Venice". However, one limitation is the separation of job and housing, which is why Radburn and some other neighborhood unit development never grew into their full expected potentials.

$<$ Figure 2. The design of the Radburn neighborhood units. $>$ Source: (Stein, C, 1958)

\subsection{Modern functionalism and economy of scale}

Both Garden Cities and Neighborhood Units intended to provide a safe way to walk in a lowdensity environment. So was the original intention of modern functionalism, despite many criticisms of its lack of emphasis on pedestrian walkability. Arose with modern functionalism, aided by the invention of steel-framed structures and vertical elevator, Le Corbusier and his Contemporary City promoted efficient urban design that favors economy of scale that warmly embraced by Fordism and Taylorism. For example, the Radiant city as shown in Figure 3. Under the modernism auspices, individualism was missing and desirable density for cities raised while compactness plummeted, even though super block has a form a walkability.

The principle of modern functionalism is to design solely based on the purpose and function of buildings. Applying this principle to urban scale planning and design, city becomes a machine for living in, as famously said by Le Corbusier. Despite what is being said, “...inspired by the arrangement and functions of the human body, cities consisted of organized parts that would work together as a whole", modern functionalism treated cities as machines more than living organisms.

$<$ Figure 3. Radiant city by Le Corbusier. $>$

\subsection{Post modernism attempts}

Under the modernism auspices, individualism was missing and desirable density for cities raised while compactness plummeted, even though super block has a form a walkability. Realizing the absent of human scale space is vital to the livability for its inhabitants and supported by environmental reformers, sustainable urban design emerged during the post-modern era and appeared in many forms: from the urban metabolism to compact cities, the charter of the new urbanism, resilient cities, and smart cities etc. The post modernism attempts also catalyzed the emergent of multi-disciplinary approaches. The rising awareness of public health, climate change, and ecological conservation progressed to experimental urban concepts of healthy cities, low carbon cities, and ecological cities. 


\subsection{Digital design paradigm and urban big data computation}

Propelled by the force of the "atom bomb" and supported by computational power of the Monte Carlo simulation and Quantum calculation, the era of digitalization and globalization embraces an era of digitalization and prediction. Wang (2018) claimed that "digital urban design not only possesses the social values and design originalities of man-machine dialogues, but also possess quantitative property and database outcomes, which can more effectively combine or even merge into the statutory urban planning system (of China)." Truly, this argument provides a prospective to treat design objectives with various spatial scales and social demands.

\section{What are walkable cities and neighborhoods?}

From garden city to the concepts of the neighborhood unit, and from post modernism experimentation to the era of digitalization, a good design always involved the intention to provide walkable urban forms. However, in reality, some urban design propositions have failed to fulfill the good intention. Learning from the past experiences, now we will discuss the spatial elements, understand spatial scales, and comprehend design dimensions that can reshape walkable cities and neighborhoods.

\subsection{Spatial elements of walkable cities and neighborhoods}

One group of scholars (Hankey and Marshall, 2010; Liu et al, 2016; Zhang et al, 2017; Guan et al, 2019) emphasized the duality of a walkable city, stating the physical (walkways, adjacent uses) and the perceived elements (safety, comfort, enjoyment). From the urban design prospective, the dichotomy of physical and the perception of the built environment cannot be separated from each other. Another group used dimension, outcomes, and proxies to summarize key factors related to walkability (Frank et al, 2005; Duncan, 2013; Forsyth, 2015). In "Walkability: what is it?", Forsyth (2015) claimed that dimensions include traversable, compact, safe for walking, and physically enticing environments; outcomes include lively and sociable, providing sustainable transportation options, and exercise-inducing features; and proxies include multidimensional in terms of means and holistic solution to improving urban environment (Forsyth, 2015). More recently, quantitative approaches have also gained substantial attention. Scholars are using metrics for the quantification of a place quality, including walkability, ecological footprint, and quality of life relating to health conditions (Legates, 2013).

\subsection{Spatial indicators of walkable city and neighborhoods}

Both individual and neighborhood measures are important spatial indicators of walkable cities. Song (2014) summarized the spatial metrics of the built environment that contribute to promoting walkable cities (Spatial elements to build walkable cities). These metrics are diversity, 
density, design, and syndetic measures. Ewing and Cervero (2010) combine diversity, density, distance to transit, destination accessibility into five D's of walkable environment.

Among the variety of individual spatial measures of walkability, connectivity is one of the most commonly used (Ellis et al, 2016). Berrigan et al (2010) claimed that the more connected the built environment, the more conducive it is to walking and sustainable mode of transport, independent of other neighborhood characteristics (Berrigan et al, 2010). Ellis et al (2016) categorized six measures of connectivity: (1) intersection density; (2) link-node ratio; (3) pedestrian route directness; (4) pedestrian shed; (5) metric reach; and (6) directional reach. Each measure informs slightly different relationship between connectivity and active travel and walkability (Ellis et al, 2016). These measures focus on street network connectivity, using either Euclidian distance or network-based time distance.

Density, including population density, residential (housing unit) density, traffic and intersection density (Frank et al, 2010), pedestrian path/foot path density (Ellis et al, 2016), public transit service density, service amenity density (Pitts et al, 2013), has also been applied to understand walkable cities. Density has been criticized of fixed spatial scales related to Modifiable Areal Unit Problem (MAUP) (Openshaw, 1989; Guan and Rowe, 2016). Because of this criticism, density is often measured together with size and location.

Diversity, the most-mentioned characteristics of a walkable city is perhaps mixed land use or diversity of the land use function. However, few have included people with diverse abilities across the age spectrum, such as seniors, children and young people (Stafford and Baldwin, 2017). Stafford and Baldwin (2017) recommended integration and inclusion of diverse ages and abilities of pedestrians into designing walkable cities. Moreover, there are also cultural, racial and ethnicity, and social diversity. All should be addressed in the planning of walkable cities.

Some recent research has found that composite measures of overall neighborhood walkability is the also predictive of physical activities, such as walk scores, indexes, and assessment models are used to evaluate walkability (Ashashank, 2015). Among them, Frank et al (2005) developed a walkability index using $1 \mathrm{~km}$ radius areas around residents' home locations. Sundquist et al (2011) also developed a walkability index.

\subsection{Design dimension, neighborhood types, and catchment areas}

While tradeoffs are made when quantifying walkable cities (Clifton et al, 2008), a recurrent concern is to translate the quality of the built environment into quantifiable measures (Forsyth et $\mathrm{al}, 2016)$. The design dimension is often undervalued to create robust and suitable results (Duncan et al, 2011). Moreover, design is also intrinsically at scale. At the neighborhood scale, design is related to architectural and landscape features. Southworth (2005) stated that these are micro variables focusing on the form and use of local places. Urban designers are designing what pedestrian sees, hears, smells, and feels of the surrounding environment (Handy, 1996). While human dimension is often promoted at a neighborhood level, city scale walkability often 
specializes in the technical aspects of transportation planning and engineering (Southworth, 2005).

Design dimensions sometimes can be systematically embedded in neighborhood types. The type of neighborhood can be categorized by location, year of built, residential units, institutional association, form and height, purpose of development, etc. For example, a historical conservation neighborhood often is centrally located with a higher percentage of senior residents. A recently built high-rise commodity neighborhood, on the contrary, are often located further away from city center. Promoting walkability and low carbon travel relies on access to public transit and the provision of retail and commercial amenities.

Design dimension is beyond the proximity theory that assuming people are walking to facilities nearby. In the theory of "walk appeal," Steve Mouzon argues that how far people will walk is all about what they encounter along the way. Some people are willing to take detours attracted by street level stores, architectural details, and street trees and to avoid surface parking and undesirable places (MIT CityLab). Walkability has always been discussed within the context of low carbon transport or health benefits, but walkability can be related to just "pleasant urbanism", meaning that people just prefer to walk in a nice environment. Perhaps it's worth to expand our understanding of design dimension to the perception aspect of walkability.

\section{Emerging themes of walkable cities}

We identified key emerging themes from research and practice of designing walkable cities. These themes are not only from urban designer's perspective but also involving knowledge of other related disciplines. They are (1) spatial scales and plurality of neighborhoods; (2) interdisciplinary methodology; and (3) the application of urban big data and computational methods. We illustrate how interventions of the emerging themes can be related to design and policy making of walkable cities.

\subsection{Spatial scale of walkability}

At neighborhood scale, spatial metrics measuring streetscape, building facade, visual complexity, enclosure, de-specialization, route choice options, and porosity have been widely used (Duncan, 2013; Meltzer, 2014; Bereitschaft, 2018; Guan et al, 2019). At the city scale, quantitative studies using empirical measures of walkability assessed diversity and land use mix, connectivity and street layout, population and housing density (Frank et al., 2010; Freeman et al., 2013). More recent studies evaluated attitude toward walkability and self-selection of relocation to build connection between scales $(\mathrm{CaO}, 2013)$. However, fewer studies have included measures of actual walking behavior at both neighborhood and city scales (Sundquist et al, 2011; Brown et al., 2013; Bereitschaft, 2018). Moreover, regional scale walkability has rarely been discussed.

\section{a. Plurality of neighborhoods}


To design walkable neighborhoods, we need to correctly identify the neighborhood in which people live, work, and play in a contemporary city. For example, an adult who commutes to work or school has at least two broadly-defined physical boundaries: one at home and the other at work or school. Traditional understanding of neighborhood walkability is related to these physical boundaries defined by the built environment or the administrative limits. However, the concept of neighborhood can also be defined by informal boundaries and cultural traditions.

Previous studies used Euclidean distance to measure the catchment area of a neighborhood (Guan and Peiser, 2018). Planning and zoning regulations also adopted a walking distance-based approach to quantify neighborhood boundaries, which led to the adoption of transit-oriented development (TOD), a catchment defined by a 5-minute or a10-minute walking shed from public transit station (Guan, 2018). More recent studies applied network distance to measure time distance of the catchment area of a neighborhood (Guan et al, 2019; Srinivasan et al, 2019). The emergent of big data such as mobile phone data and GPS enabled devices enabled us to capture the real catchment areas of a neighborhood at an individual user's level. The plurality of a neighborhood is also related to its functional, perceptions of dwellers, and frequency of uses.

A literature exists that captures the spatial lens of the ideal typical neighborhood through which the city can be disaggregated. In contrast we can experiment with the plural data driven definitions informal neighborhoods that can be understood as social material systems in their own right; defined materially through multiple techniques of remote sensed data, imaging, and telephone records; socially through symbolic and cultural definitions of thresholds investigated ethnographically, boundaries and iconography and in statutory form through bundled and plural property rights defined through speculative architectural inquiry.

\section{b. Spectrum of activities (SOA)}

The spectrum of activities for different user groups should be identified to address their particular needs of walkable cities and neighborhoods. Namely, based on age - young adults versus seniors; based on length of stay - visitors versus residents; based on mode of travel -

pedestrian, runner, and cycler. We can target the specific areas that involving high user intensity and group characteristics that require special attention. For example, previous studies have adopted different walk scores for tourists and residents. Figure $\mathbf{4}$ shows a map of locals versus tourists created by Eric Fischer using Twitter data and MapBox. It reveals that promoting walkability targeting tourists and locals need different accommodations. We emphasize the type of neighborhood and type of street (Measuring the completeness of complete streets).

$<$ Figure 4. Locals and visitors' neighborhood - spatial distribution map using Twitter data.>

\section{c. Public space/amenities catchment area delineation}

Designing walkable city also involves improved understanding of public service catchment areas. The concept of a catchment area (or service area) is defined as the area from which a city, 
service or institution attracts a population that uses its services. Powered by urban big data and the growing shared economy, we are able to reevaluate the catchment areas using real time GPS data, see Figure 5. Connect this back to the Garden city concept, for example, how to create urban park networks to give a reason for people to walk.

$<$ Figure 5. Delineation of urban park catchment area. $>$

\subsection{Walkable city and neighborhood as a multi-disciplinary approach}

Systemic measures of walkable city require a multi-disciplinary approach. Jeff Speck (2018) in his Walkable City Rules identified the following disciplinary approaches of designing walkable cities: Health, transportation, ecology, in addition to economic (such as walkability and home value) and social equity. We follow these categorizations by further exploring the health value, transportation, and ecological value of walkable cities and neighborhoods.

\section{a. Health value of walkable cities}

As obesity has now become a major public health problem in the United States, several studies have made connections between health and the design and planning of cities (Frank and Engelke, 2001; Ewing et al, 2003). Of many things that affect obesity and associated health impacts, three major factors believed to contribute to obesity are metabolic factors, diet, and physical activity (Weinsier et al., 1998). Recently, there has been increasing attention on the role of physical activity and how sedentary lifestyle in many Westernized nations has contributed to the obesity epidemic (Chin et al., 2016). Thus, promotion of physical activity at the population level has been one of the most important public health goals. World Health Organization (WHO) currently has a recommended guideline for physical activity to maintain active and healthy life style, which is to spend at least 150 minutes of moderate and vigorous physical activity (MVPA) per week (WHO, 2011). Common activities that require some level of physical exertion are classified as MVPA, such as brisk walking, jogging, cycling, and playing sports. However, achieving this minimum level of physical activity on a daily basis is probably the most challenging target for many people in many Westernized nations. Modern life style and workforce puts very little demand for physical activity, and to achieve the minimum recommended levels of physical activity, we consciously need to make time to include exercise as part of our daily routine. One way to achieve this level of fitness at the population-level is to design our cities in such a way that would make walking and cycling a natural choice. For this reason, the concept of walkability and walkable cities has gained considerable attention in the public health communities (Dannenberg et al, 2003; Jackson et al, 2013), and walkability has been incorporated into the health assessment framework (de Nazelle et al, 2011).

\section{b. Transportation and walkable cities}


In Low Carbon Transportation, Jia (2017) discussed induced traffic, number of street lanes, walkable block size, bike lanes (bicycle population is the function of bicycle infrastructure), parking as buffer of bike lanes, trees slow cars down. The concept of walkable city is not new as walking is a fundamental aspect of human locomotion and transportation. Being able to walk freely and safely, however, has been challenging in many cities around the world as large part of our urban spaces has been dedicated to automobiles. There has been an increasing awareness that auto mobility is a serious problem that contributed to the current obesity epidemic. Time spent in cars has been identified as a risk factor for obesity (Frank et al, 2004), and recent studies have reported significant health gain can be achieved by replacing car trips with more active forms of transport, such as walking, cycling (Rojas-Rueda et al, 2012), and public transportation (Rissel et al, 2012; Hong et al, 2016). Therefore, an active form of transport constitutes an important element of designing a walkable city. Yet, there is a problem of incorporating active transportation in many cities. Better designing of urban and transport systems can lead to more cycling, walking, and transit use; however, it can inevitably increase exposure to harmful emissions by placing people closer to traffic (Hankey and Marshall, 2019). It is, therefore, of critical importance for the urban design and planning communities to consider both physical activity aspects and air pollution exposure aspects of a walkable city design (Frank et al, 2019). An integrated framework, such as the one suggested by Frank et al (2019), will likely help us design cities that would maximize the benefits of active transportation while minimizing the risks associated with it.

\section{c. Ecological value of walkable cities}

Environmental benefits of active transportation have been widely discussed. Hong (2018) argued that first active modes of transport requires less space; second it produces fewer emissions per capita or per passenger travel distance; third it produces lower life cycle costs. Forman (2014) in his book Urban Ecology - Science of Cities provided plausible solutions to increase walkability and preserve ecological values in an urban environment. These solutions can be summarized into urban ecological principles that promoting the design and planning of walkable cities. If aligning the design walkable cities with political interest such as the Paris Agreement towards reducing the risks of climate change, we can qualify the achievement of long-term goals of keeping people on their feet and low carbon modes of travel.

\subsection{Urban big data and computation in designing walkable city}

The application of urban big data in designing walkable city has created new opportunities to understand city and components of city in an innovative perspective. In addition to the abovementioned delineating catchment area using mobile phone data, there are many prospects of using individual personal level data to design walkable cities and neighborhoods. First, GPS enabled sensor data. For example, mobile phone carriers' user location data; sensors data 
acquired from equipment installed in bicycles, buses, and other type of public transit; modes specific data such as runners and hikers, see Figure 6. Second, social media, crowd sourcing, and smart phone application data. For example, Twitter, Facebook, and Weibo are good examples of social media data. WhatsApp and WeChat (mainly in China) are good examples of instant messaging apps installed in smart phones. Third, economic activity data. For example, consumer transaction data using credit cards. There are also the more conventional real estate property data and those data involved with cutting edge technologies such as artificial intelligence and neural networks.

$<$ Figure 6. Runner's neighborhood - activity heat map produced using Strava data.>

As Batty (2013) stated, the idea of designing walkable, smart, and sustainable city relies on the potential of integration of the data from different sources and turning them into useful information. Truly, the raw data collected may not be of use at all, however, through the processes of cleaning, filtering, selection, combination, and transformation, we can generate knowledge, recognizing, and intelligence towards designing better and more effective walkable city strategies (Batty, 2013). For example, we can apply individual user level data with urban built environment data to discover the latent function of urban public facilities. We can provide policy interventions in the realm planning and design to promote walkability. The task doesn't stop here, however, the post processing stage starts by accumulating new knowledge generated. The continuous building of databases can be critical to monitor and produce newer knowledge constantly. The issues remains are privacy, inaccuracy (user and activity), and inconsistency (space and time).

\section{Conclusion}

In sum, the urban planning and design propositions promoting walkable city can be traced back to at least the garden cities of tomorrow. Learning from the past and observing the present, we should discuss the spatial elements, understand spatial scales, and comprehend design dimensions that can reshape walkable cities and neighborhoods. More importantly, we can identify key emerging themes from research and practice of designing walkable cities. We recognize that these themes are not only from urban designer's perspective but also involving knowledge of other related disciplines.

Looking ahead to the future, we should revisit and emphasize the following aspects of walkable cities and neighborhoods: (1) Cities should be walkable. In a chronological order, we categorized the discourse of walkable cities into garden cities, neighborhood units, modern functionalism and economy of scale, and post modernism attempts. How can lessons and information from these past stages of urban development inform the current practice defined as digital design paradigm and urban big data computation deserved more attentions. (2) Walkable 
city has multiple spatial and temporal scales and are multi-disciplinary in nature. We need to reconsideration the spatial dimensions of a neighborhood, the spectrum of activities associated with different users, and the function of urban facilities in relation to their catchment areas. The emerging themes of such investigation can be applied to public health, transportation and land use, and urban ecology. (3) Urban big data and computational methods can reveal walkable city of the future. The scarcity of urban big data in the study is partially due to the scarcity of available data and computational power. However, the emergent of crowd sourcing data, open source data, and GPS enables devices and sensors have significantly changed the situation in the last decades. The new challenge is on data fusion algorithms to synthesize heterogeneous data sources from multiple disciplines. For example, Important empirical methods and the emergent of urban big data can provide us more detailed information of a diversified inhabitants and the built environment. We can adopt new methods and data to enlighten the design of walkable cities and neighborhoods. These perspectives can inform future studies of designing walkable cities and neighborhoods.

\section{References}

Batty, M. (2013) Big data, smart cities and city planning. Dialogues in Human Geography, 3(3), 274-279.

Bresnehan, MA (1995) The effectiveness of public open space systems within the "Radburn"suburb. Case study: Rokeby, Research Master thesis, University of Tasmania.

Chin, S, Kahathuduwa, C. and Binks, M. (2016) Physical activity and obesity: what we know and what we need to know. Obesity Reviews, 17, 1226-1244.

https://onlinelibrary.wiley.com/doi/full/10.1111/obr.12460

Dannenberg et al (2003) The Impact of Community Design and Land-Use Choices on Public Health: A Scientific Research Agenda. American Journal of Public Health, 93(9) 1500-1508. https://ajph.aphapublications.org/doi/full/10.2105/AJPH.93.9.1500

de Nazelle et al (2011) Improving health through policies that promote active travel: A review of evidence to support integrated health impact assessment. Environmental International, 37(4) 766-777. https://www.sciencedirect.com/science/article/pii/S0160412011000341

Duncan D.T. (2013) What's your Walk Score®?: Web-based neighborhood walkability assessment for health promotion and disease prevention. Am. J. Prev. Med, 45:244-245. doi: 10.1016/j.amepre.2013.04.008

Frank L, Andresen, M, and Schmid, T (2004) Obesity relationships with community design, physical activity, and time spent in cars. American Journal of Preventive Medicine, 27(2), 8796. https://www.sciencedirect.com/science/article/pii/S074937970400087X

Frank L et al (2005) Linking objectively measured physical activity with objectively measured urban form: Findings from SMARTRAQ. American Journal of Preventive Medicine, 28, 2 , 117-125.

Frank, D, Iroz-Elardo, N, MacLeod, K, and Hong, A (2019) Pathways from built environment to health: A conceptual framework linking behavior and exposure-based impacts. Journal of 
Transport \& Health, 12, 319-335.

https://www.sciencedirect.com/science/article/pii/S2214140518303360

Frank, D. and Engelke, P. (2001) Exploring the Impacts of Urban Form on Public Health. Journal of Planning Literature, 16(2) 202-218. https://journals.sagepub.com/doi/abs/10.1177/08854120122093339

Forman, R (2014) Urban Ecology - Science of Cities. Cambridge University Press, New York.

Guan, C (2018) Spatial distribution of high-rise buildings and its relationship to public transit development in Shanghai. Transport Policy. In press.

https://doi.org/10.1016/j.tranpol.2018.09.004

Guan, C and Peiser, R (2018) Accessibility, urban form, and property value: A study of Pudong, Shanghai. Journal of Transport and Land Use, 11(1) 1057-1080. http://dx.doi.org/10.5198/jtlu.2018.1318

Guan, C., Srinivasan, S., and Nielsen, C. (2019). Does neighborhood form influence low-carbon transportation in China? Transportation Research Part D: Transport and Environment, 67, 406-420. https://doi.org/10.1016/j.trd.2018.12.015

Hankey, S and Marshall, J (2017) Urban Form, Air Pollution, and Health. Current Environmental Health Reports, 4(4) 491-503.

https://link.springer.com/article/10.1007\%2Fs40572-017-0167-7

Hong, A (2018) Environmental Benefits of Active Transportation. Children's Active Transportation. 21-38. https://doi.org/10.1016/B978-0-12-811931-0.00002-8

Hong, A, Boarnet, M, and Houston, D (2016) New light rail transit and active travel: A longitudinal study. Transportation Research Part A: Policy and Practice, 92, 131-144. https://www.sciencedirect.com/science/article/pii/S0965856416306309

Jackson R, Dannenberg, A, and Frumkin H (2013) Health and the Built Environment: 10 Years After. American Journal of Public Health, 103(9) 1542-1544. https://ajph.aphapublications.org/doi/abs/10.2105/AJPH.2013.301482

Maurice de Soissons, Welwyn Garden City, Cambridge, Publications for Companies, 1988

https://www.theguardian.com/sustainable-business/2015/apr/20/garden-cities-can-green-spacesbring-health-and-happiness

Peck, J (2013) Walkable City: How Downtown Can Save America, One Step at a Time. North Point Press, New York.

Pitts, S.B.; Carr, L.J.; Brinkley, J.; Byrd, J.L., 3rd; Crawford, T.; Moore, J.B. Associations between neighborhood amenity density and health indicators among rural and urban youth. Am. J. Health Promot. 2013, 28, e40-e43.

Rissel, C, Curac, N, Greenaway, M, and Bauman A (2012) Physical Activity Associated with Public Transport Use-A Review and Modelling of Potential Benefits. International Journal of Environmental Research and Public Health, 9, 2454-2478.

https://www.ncbi.nlm.nih.gov/pmc/articles/PMC3407915/

Rojas-Rueda, D, de Nazelle, A, Teixido, O, and Nieuwenhuijsen, M (2012) Replacing car trips by increasing bike and public transport in the greater Barcelona metropolitan area: A health impact assessment study. Environment International, 49, 100-109.

https://www.sciencedirect.com/science/article/pii/S0160412012001833 
Sallis et al (2016) Physical activity in relation to urban environments in 14 cities worldwide: a cross-sectional study. The Lancet, 387 (10034) 2207-2217.

Srinivasan, S., Guan, C., and Nielsen, C. (2019) Built environment, income and travel behavior: Change in the city of Chengdu, China 2005-2016. International Journal of Sustainable Transportation. In Press.

Stafford, L and Baldwin C (2017) Planning Walkable Neighborhoods: Are We Overlooking Diversity in Abilities and Ages? Journal of Planning Literature, 33, 1.

Talen, E. and Koschinsky, J. (2013) The walkable neighborhood: A literature review. International Journal of Sustainable Land Use and Urban Planning 1(1): 42-63.

Wang, J. (2018) Four generations of urban design paradigm from a rational planning perspective. Urban Planning International.

Weinsier et al (1998) The Etiology of Obesity: Relative Contribution of Metabolic Factors, Diet, and Physical Activity. The American Journal of Medicine, 105(2), 145-150. https://www.sciencedirect.com/science/article/pii/S0002934398001909

World Health Organization. (2011) Global recommendations on physical activity for health. Geneva, Switzerland. https://bit.ly/2J33O2k

Koschinsky J, Talen E, and Alfonzo M (2017) How walkable is Walker's paradise? EPB.

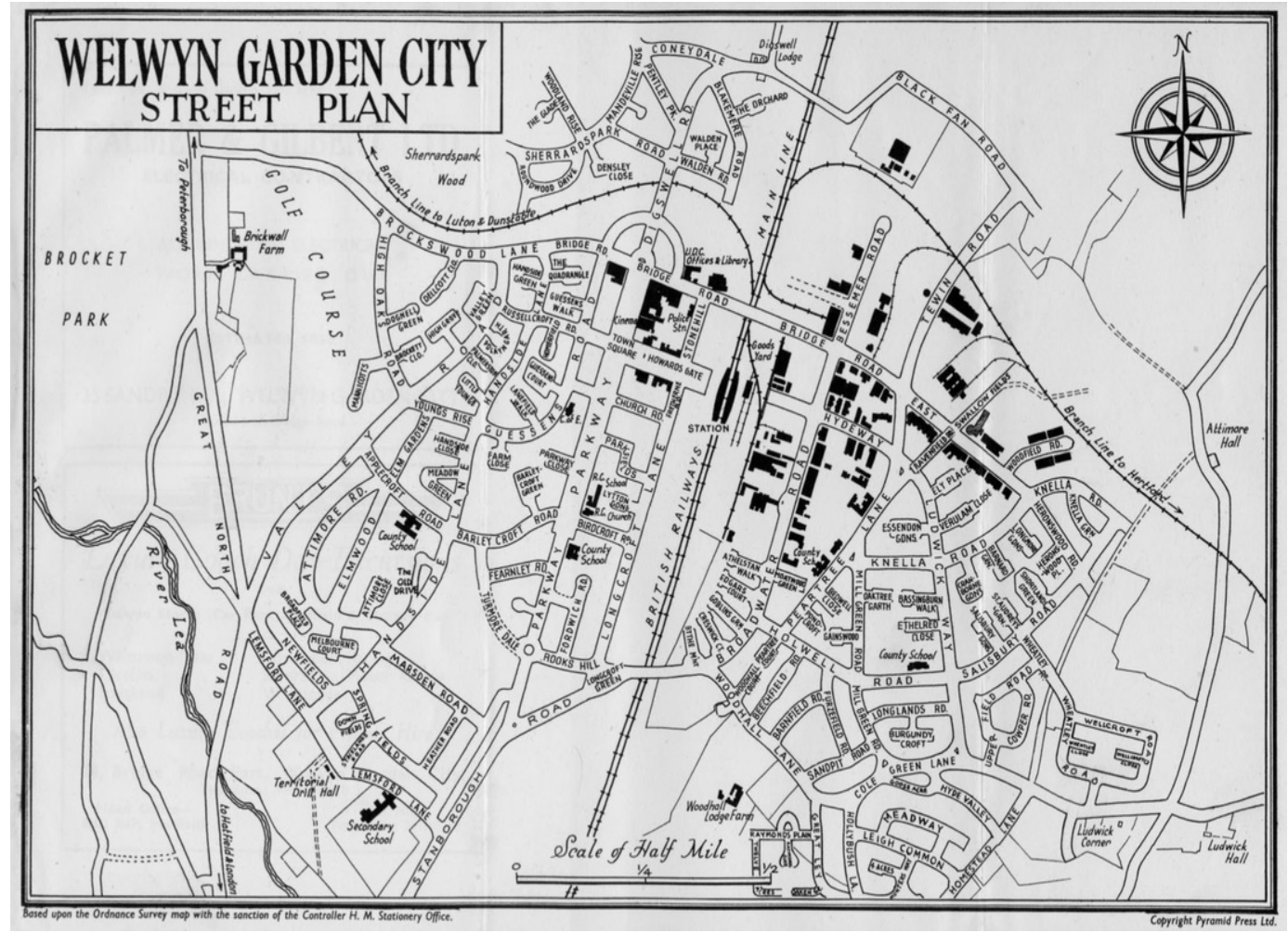

Figure 1. Welwyn Garden City: the self-sufficient and walkable city. 


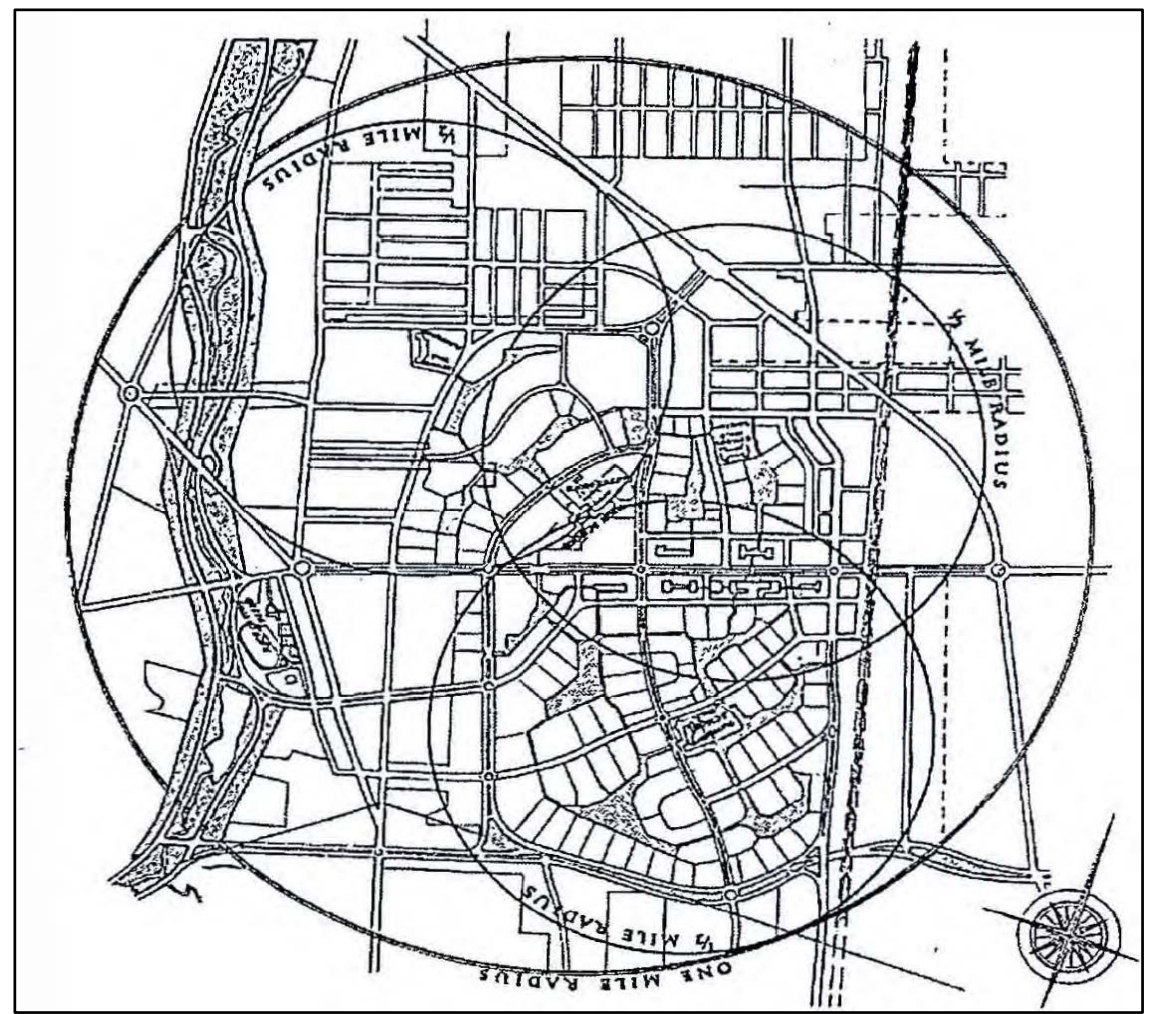

Figure 2. The design of the Radburn neighborhood units

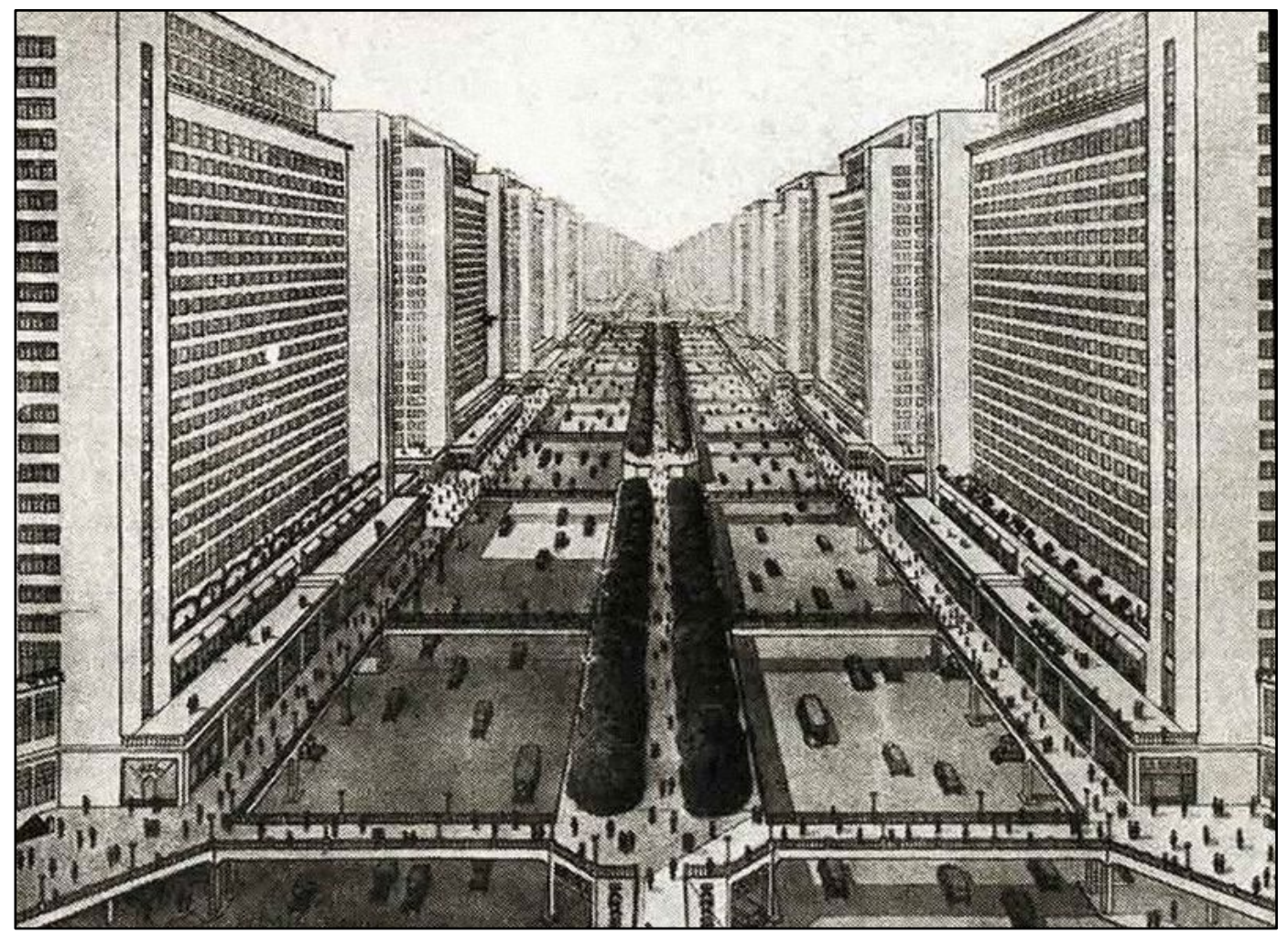

Figure 3. Radiant City. 


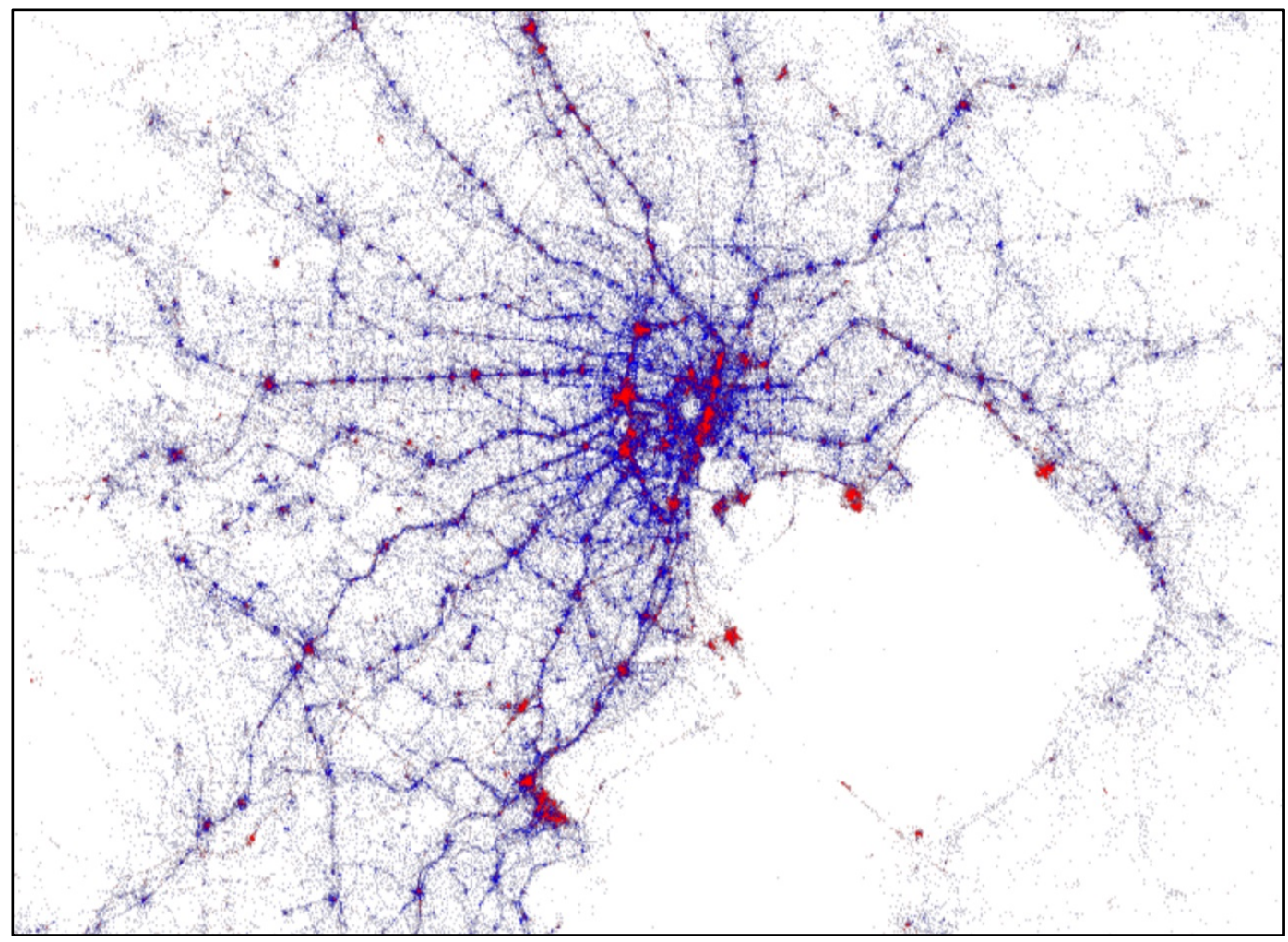

Figure 4. Locals and visitors' neighborhood - spatial distribution map using Twitter data. Source: Eric Fischer using Twitter data with MapBox.

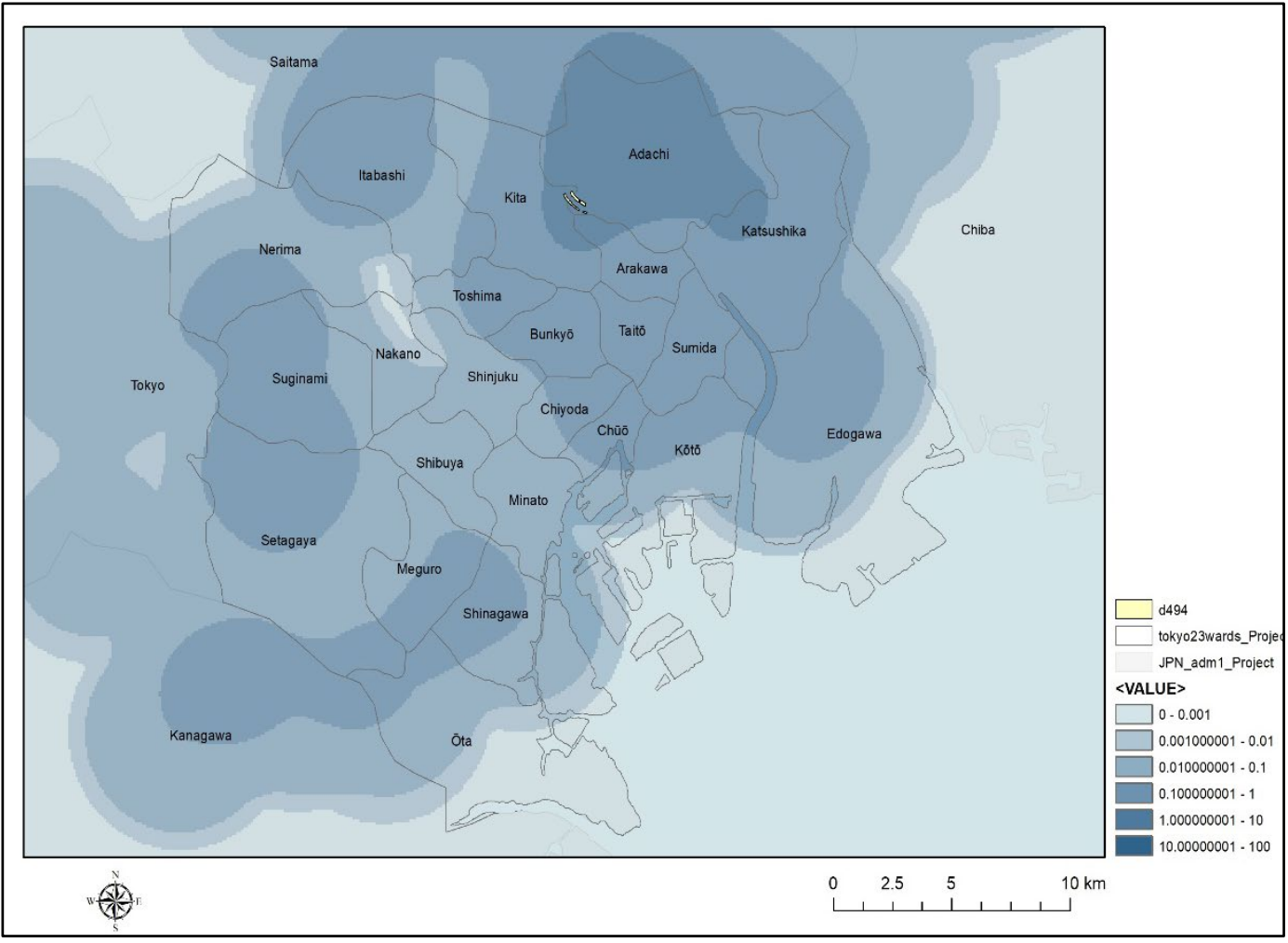

Figure 5. Delineation of urban park catchment area. Source: Authors. 


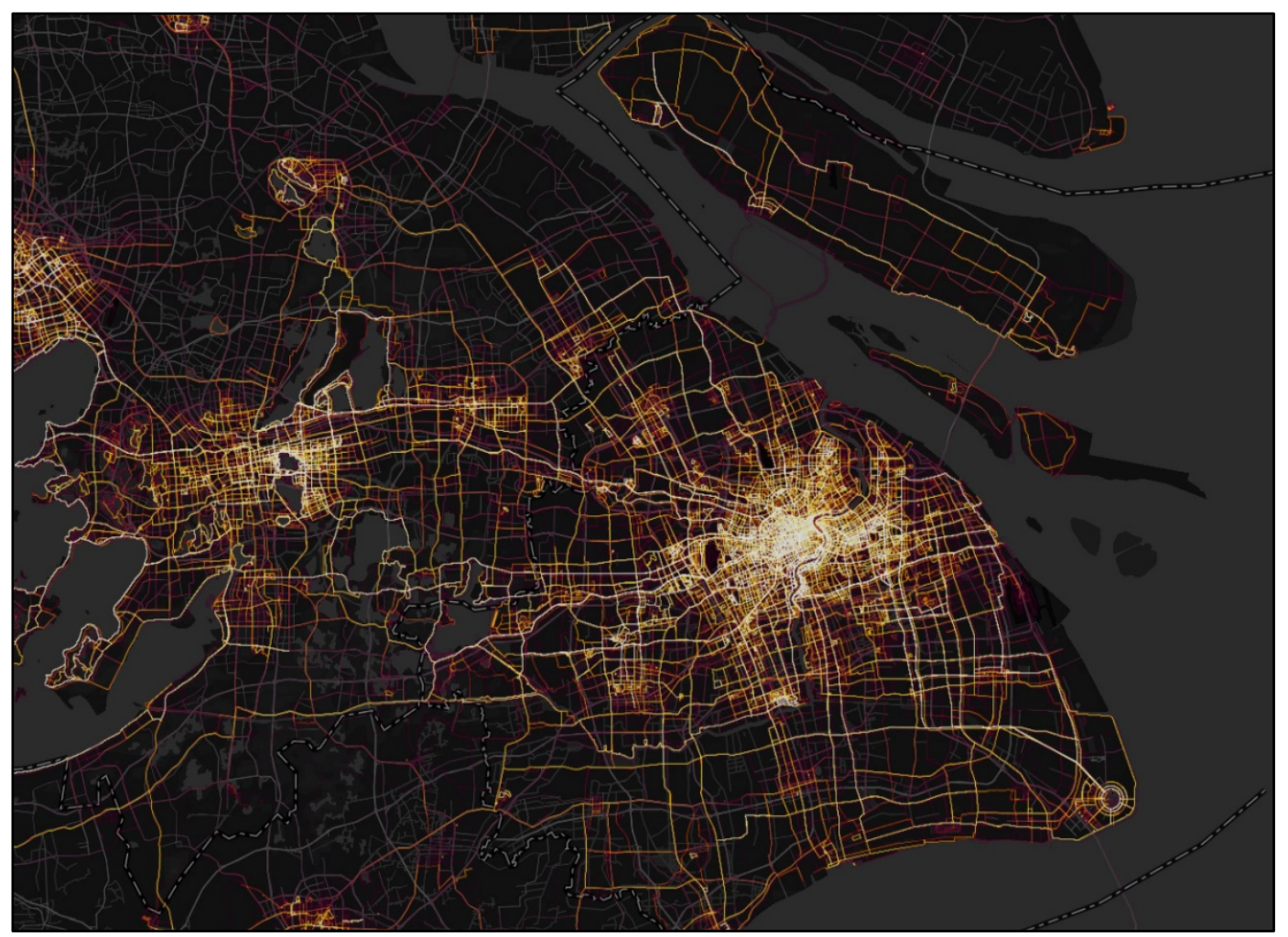

Figure 6. Runner's neighborhood - activity heat map produced using Strava data. Source: Strava. 